\title{
To the readers of the first issue of Acta Naturae
}

7 e present the first issue of a new jour$\checkmark$ nal covering a wide range of problems related to life sciences. What could be the purpose of one more journal focused on these issues? The advanced capabilities of the Internet allow us to see hundreds of publications with various "impact factors" in the sphere of biomedical science. There are quite reputable and serious journals with long-standing histories. Every year, the number of these journals increases. It is rather difficult for journals to find their own niche and demonstrate originality. Nevertheless, we decided to publish a national journal in both Russian and English and hope that it will be of interest to our readers. Our hope is based on the likely interest of both Russian and foreign readers to the recent developments of the most advanced laboratories and scientific centers of Russia. This peer-reviewed information will be presented as brief journal reports. In spite of pessimistic prognoses, Russian science survived the deep crisis of the 1990s and, in the last 3-4 years, many academic and university centers have showed progress in their development thanks, in large part, to an increase in domestic financial support and specific personnel decisions. Reviews of invited foreign and Russian authors devoted to the actual problems of biomedical science will be the second-most important constituent of our new journal. We believe that these sections will be of interest to both young students and veteran researchers. We don't plan on avoiding the social and organizational aspects of scientific development, either. Hence, we are planning to publish interviews with leading scientists, representatives of business interested in knowledge-intensive production, and officiaries. Hopefully we'll manage to create a tribune for discussing the relevant aspects of scientific development in Russia. We are aware that "living science" is closely related to the applied aspects of biopharmaceutics, and it is not improbable that the lack of information and awareness of Russian researchers in this sphere will be compensated for by our journal. We would like to see representatives of Russian and foreign biopharmaceutical businesses as authors in our new journal. If we succeed, we hope to see experimental articles by foreign authors on the pages of Acta Natura to make it more international.

We wish all the readers of our new journal success in their scientific studies and practical work, and we are looking forward to cooperating with them.

Editorial Board 